\title{
Estudio de factibilidad para la creación de un restaurante sustentable en el cantón General Villamil Playas
}

\section{Feasibility study for the creation of a sustainable restaurant in the canton General Villamil Playas}

Econ. Rossana Ricaurte Párraga, MBA

Ing. Jorge Armanza Ochoa, MBA

John Solórzano Cedeño

Universidad de Guayaquil, Ecuador

Autor para correspondencia: rossana.ricaurtep@ug.edu.ec,jorge.armanzao@ug.edu.ec

Fecha de recepción: 12 de Junio de 2017- Fecha de aceptación: 15 de Noviembre de 2017

Resumen: Una preocupación latente a nivel mundial estriba en el desperdicio inmensurable de alimentos provocado principalmente por un ineficiente proceso en la cosecha y en la preparación de los alimentos; es por ello que ésta investigación tuvo como objetivo principal estudiar la factibilidad de la creación de un restaurante sustentable en la Ciudad Villamil Playas, la cual permitirá a los profesionales de la gastronomía contar con una guía que les ayude a incursionar en proyectos que no sólo sean rentables sino también generen un aporte social, turístico y ambiental para el desarrollo local y regional. La metodología usada se basó en un estudio descriptivo y exploratorio que permitió conocer la aceptación del negocio en ésta localidad, así como también se hizo uso a las investigaciones previas de diversos autores relacionadas al tema. La propuesta incluye los mecanismos que podrían ser implementados en éste tipo de proyecto tales como: la creación de un huerto orgánico destinado a la siembra y cosecha de productos libres de pesticidas, la implementación de paneles solares que ayuden al ahorro energético, un plan de ahorro y consumo necesario de agua y la responsabilidad de manejar un adecuado proceso de reciclaje; esto ayudaría a incentivar a la sociedad a ser responsable con el uso de recursos y rescatar los hábitos de una alimentación sana. Adicionalmente la propuesta también proyecta datos económicos como la inversión necesaria para el proyecto, ingresos, egresos, punto de equilibrio, indicadores de evaluación financiera (VAN y TIR) así como el período de recuperación del capital; cálculos que garantizan la sustentabilidad del negocio en el largo plazo debido al uso de recursos renovables lo cual ayuda principalmente en la reducción de los costos de producción.

Palabras clave: emprendimiento; cocina sustentable; productos orgánicos; viabilidad

Abstract: A deep concern at global level lies in the immeasurable waste of food caused mainly by an inefficient process in harvesting and preparation of food. This is the main reason why this research had as main objective to study the feasibility of creating a sustainable restaurant in the City Villamil Playas in Ecuador, which will allow gastronomy professionals to have a guide that helps them to work into projects that are not only profitable but also generate a social, touristic and environmental contribution for local and regional development. The methodology used was based on a descriptive and exploratory study that allowed to know the acceptance of the business in this locality, as well as it was used to the previous investigations of diverse authors related to the subject. The proposal includes the mechanisms that could be implemented in this type of project such as: the creation of an organic orchard for planting and harvesting pesticide-free products, the implementation of solar panels that help to save energy, a savings plan and necessary water consumption and the responsibility of handling an adequate recycling 
process; this would help to encourage society to be responsible with the use of resources and to rescue the habits of a healthy diet. In addition, the proposal also schemes economic data such as the investment necessary for the project, income, expenses, break-even point, financial evaluation indicators (NPV and IRR) as well as the period of capital recovery; calculations that guarantee the sustainability of the business in the long-term due to the use of renewable resources which helps mainly in the reduction of production costs.

Key words: entrepreneurship; sustainable cooking; organic products; feasibility

\section{Introducción}

El Instituto Nacional de Estadística y Censos (INEC) en su Encuesta Nacional de Ingresos y Gastos en Hogares Urbanos y Rurales 2011-2012 (Enighur) determina que de los gastos de consumo promedio de $\$ 584$, se destina el $24,4 \%$ a la adquisición de alimentos y bebidas no alcohólicas; se puede inferir entonces que el sector de alimentos y bebidas sea considerado como uno de los sectores más importantes dentro de la Economía Ecuatoriana.

Sin embargo, existe una preocupación latente a nivel mundial, regional y local sobre la cantidad de desperdicios causada en la producción de alimentos para el consumo humano, lo que origina severos daños al medio ambiente: calentamiento global, alta concentración de CO2, cambios estacionales, entre otros. Según $\mathrm{FAO}^{1}$ (2012), un tercio de todos los alimentos producidos para consumo humano en el mundo se desperdician o desechan, sumando un total de 1.3 billones de toneladas.

La Organización Internacional del Trabajo (2014) concluye lo siguiente: Reducir los desperdicios es uno de los mayores retos para la industria restaurantera pero no sólo por las pérdidas de alimentos y los despilfarros de dinero, sino también porque hoy en día se tiene un nuevo consumidor, el consumidor consciente, aquel que se preocupa por el origen de sus alimentos y por conocer dónde terminan. (p. 1)

El estilo de cocinar y presentar los platos en el Ecuador, se orientan al estilo Nouvelle Cuisine, estilo que nace en Francia en los años 70s y se populariza en el resto de continentes en los años 80s, cuya filosofía es la presentación de platos más livianos y delicados, sin salsas pesadas, ni vegetales cocidos en exceso.

Esta orientación a la presentación, ha provocado la poca atención en el cuidado al medio ambiente canalizado a través de un adecuado proceso de gestión de desperdicios, enfoque que ya está siendo liderado por países desarrollados al incursionar en proyectos sustentables; de ésta manera surge la iniciativa que motive al cambio de conciencia para que los restaurantes a nivel local y nacional sean eco-amigables con la Naturaleza.

Esta investigación tiene como objetivo central proponer la creación de un restaurante sustentable en el Cantón General Villamil Playas, iniciativa que nace con el fin de brindar una herramienta que les permita a los profesionales del sector gastronómico incursionar en negocios sostenibles que generen un valor social, ambiental y turístico.

\footnotetext{
${ }^{1}$ Organización de las Naciones Unidas para la Alimentación y la Agricultura
} 
La investigación utilizada fue de tipo exploratoria y descriptiva mediante el cual se hicieron uso de las siguientes técnicas: observación, fuentes bibliográficas. La propuesta incluye la creación de un huerto orgánico destinado a la siembra y cosecha de productos libres de pesticidas, la implementación de paneles solares que ayuden al ahorro energético, y un plan de ahorro y consumo necesario de agua y la responsabilidad de manejar un adecuado proceso de reciclaje; esto ayudaría a incentivar a la sociedad a ser responsable con el uso de recursos y rescatar los hábitos de una alimentación sana. Por tanto, se hizo necesario realizar un estudio de mercado (análisis de la viabilidad comercial), estudio estratégico (análisis interno y externo), estudio de mercado (estrategias de promoción), estudio técnico - administrativo y un estudio financiero (análisis de la rentabilidad del proyecto y recuperación del capital).

\section{Desarrollo}

\section{Estudio del Marco Teórico}

Se hizo necesario abordar el estudio del arte en torno a las definiciones brindadas por diversos autores sobre desarrollo sustentable. En éste contexto, Calvente (2007) aporta que el término "sustentabilidad" sufrió diferentes transformaciones a lo largo del tiempo hasta llegar a un concepto moderno basado en tres dimensiones: la económica, la social y la ambiental. (p. 1).

Villamizar, es recogido por Cortés and Peña (2015), refiere al desarrollo sustentable como un proceso integral que exige a los distintos actores de la sociedad compromisos y responsabilidades al aplicar mecanismos económicos, políticos, ambientales y sociales, así como en los patrones de consumo que determinan la calidad de vida. Requiere el manejo de recursos naturales, humanos, sociales, económicos y tecnológicos, con el fin de alcanzar una mejor calidad de vida para la población, y al mismo tiempo, velar porque los patrones de consumo actual no afecten el bienestar de las generaciones futuras. (p. 2).

El Instituto Boliviano de Comercio Exterior (2013) aborda que para que un negocio sea sustentable debe participar en actividades amigables con el ambiente para asegurar que todos los procesos, productos y operaciones de manufactura que consideren los retos ambientales y que al mismo tiempo produzca un beneficio económico.

En la actualidad, muchas empresas están rediseñando sus modelos de negocios hacia uno que contemple prácticas de sustentabilidad, en éste sentido Prado (2013) asegura que en la construcción de modelos de negocios sostenibles se hace necesario crear valor para los stakeholders (en contraposición al modelo tradicional que busca el valor exclusivamente para los clientes y la empresa) y como captura ese valor la empresa.

Los negocios gastronómicos también apuestan en ofrecer un valor agregado a sus grupos de interés, ya que han logrado comprender lo que plantea Ramírez (2016), la gastronomía no sólo se basa en la transformación de alimentos, sino que existen otros elementos culturales, sociales, económicos, políticos, ambientales que la integran. (p. 5).

De acuerdo con vidasostenible.org, la cocina sostenible es entendida como una técnica de acopio, uso y transformación de los alimentos basada en el conocimiento de su origen y de sus 
consecuencias para la salud personal, social, ambiental y económica de nuestro planeta. Indaga en los orígenes de los alimentos que utiliza, y en las cadenas de transformación que han sufrido hasta llegar a ser comercializados, eligiendo los mejores para la salud y el planeta; de ésta manera utiliza la información disponible y la tecnología para llevar a cabo la transformación de los alimentos acopiados en comida sana y apetecible, con la mayor eficiencia energética e hídrica posible y con una producción de residuos reducida al mínimo.

A nivel internacional, ya existen algunas iniciativas interesantes. Por ejemplo, agrotravelturismoresponsable.wordpress.com expone el caso de "Slow Food"; el cual cuenta con más de 100,000 asociados en más de 120 país. Su filosofía se fundamenta en que la agricultura sostenible es la condición indispensable para salvaguardar la naturaleza, ya que ésta minimiza los daños al medio ambiente reduciendo la contaminación, genera alimentos más nutritivos, recupera aquellos ingredientes en vías de extinción y posibilita un comercio de precios justos reforzando la economía local promoviendo el consumo de ingredientes de proximidad: una manera de apoyar a los agricultores y ganaderos locales, de estimular los huertos propios, así como a las pequeñas industrias de elaboración artesanal, defendiendo un cultivo sin transgénicos y respetando sobre todo los productos de temporada que en definitiva son los que más necesitamos en cada estación. Desde el movimiento Slow Food, un grupo de cocineros han creado una red de restaurantes denominados KM.0. Lo distintos de estos platos es que el $40 \%$ de los ingredientes que los integran son producidos en menos de 100 kilómetros, o que el $60 \%$ son producidos lo más cerca posible, y los que no, son de producción ecológica. Para obtener este distintivo es necesario tener un mínimo de 5 platos en la carta que se ajusten a esta filosofía. Existen en España 24 restaurantes y 60 cocineros KM.0.

En el Ecuador, el Gobierno en su Plan Nacional del Buen Vivir 2013-2017 contempla la transformación productiva bajo un modelo eco eficiente con mayor valor económico, social y ambiental; para lograrlo se plantean como prioridades la conservación y el uso sostenible del patrimonio natural y sus recursos naturales, la inserción de tecnologías ambientalmente limpias, la aplicación de la eficiencia energética y una mayor participación de energías renovables, así como la prevención, el control y la mitigación de la contaminación y la producción, el consumo y el pos consumo sustentables.

Existen varias normas de sustentabilidad al interior del país, y específicamente en el sector de Alimentos y Bebidas se puede citar a la Norma Técnica 3010:2015 "Restaurantes. Sistema de gestión de la calidad y el ambiente requisitos"; documento elaborado por el Servicio Ecuatoriano de Normalización; el cual aborda la necesidad de que las prácticas ambientales deben estar ligados a los siguientes parámetros:

- Control de consumo de energía: Enfocadas a establecer mecanismos para el ahorro de energía, la verificación permanente de los equipos e instalaciones a través de un mantenimiento preventivo, la utilización de sensores y temporizadores que apaguen automáticamente las luces innecesarias

- Control de consumo de agua: Revisión periódica de las instalaciones para localizar fugas, instalación de equipos que permitan ahorrar el consumo de agua, evasión de prácticas paisajísticas que realizan un consumo excesivo del agua, procesamiento por separado de 
los desagües de aceite y grasas, la minimización del cloro, detergentes y sustancias contaminantes.

- Gestión de residuos: Clasificación de los tipos y cantidades de basura que se producen, para así establecer métodos para su eliminación, elaboración de un programa de gestión de residuos sólidos basado en la estrategia de las tres R: Reducir - Reutilizar y Reciclar, la recuperación de artículos como el papel, el vidrio, el aluminio y el plástico, la transformación de los restos de comida, las hojas y los restos de plantas en abono orgánico, la colocación de cestos en lugares estratégicos.

- Utilización de productos químicos y políticas de compras: Establecimiento de límites de la cantidad de residuos que se generan por el uso de los productos químicos que se utilizan en el establecimiento, la reducción de los agentes contaminantes empleando productos naturales como la sal, el vinagre y el bicarbonato para limpiar (hornos, desagües, ventanas y suelos, entre otros), el uso de productos de limpieza, pinturas, disolventes y productos compatibles con el ambiente.

Otra interesante práctica en los restaurantes sostenibles consiste en contar con un Huerto Orgánico. El Instituto de Medio Ambiente Gylanta (2001), define al huerto orgánico como un sistema de cultivo de hortalizas, en el cual se trabaja de acuerdo a los principios de la naturaleza. Mientras que en la agricultura tradicional hoy en día se trabaja según el sistema: “¿Qué puedo exigir de la tierra?", el huerto orgánico pertenece a la agricultura ecológica que funciona según el sistema: “Qué me puede dar la tierra?”

El Ministerio de Agricultura y Pesca (2013) define los siguientes principios para un huerto orgánico familiar:

- Un buen huerto funciona cuando recibe todos los residuos de la finca: el excremento de los cuyes, vacas, chivos, caballos, y lo que sale del deshierbe de la finca y los desechos orgánicos de la cocina.

- Tiene que ser diverso, tener la mayor cantidad de especies y asociado. Al asociar unas plantas con otras se están protegiendo de plagas y se están alimentando.

- Tiene que ser muy productivo. Mejorando las semillas locales y recuperando plantas comestibles y medicinales de la zona o región.

- Tiene que ser lo máximo autónomo y autosuficiente. Tiene que producir su propio abono y su propia semilla, sus propias medicinas (fungicidas, insecticidas). La familia debe aportar en conjunto para tener un buen huerto, siempre sembrando y siempre cosechando. La idea es reducir la necesidad de dinero para las compras de insumos.

Finalmente, el Gobierno del Ecuador reconocerá a través de ciertos incentivos a las empresas que implementen prácticas ambientales. El Ministerio del Ambiente a través de su página web menciona entre ellos la Certificación Punto Verde, la cual otorga los siguientes beneficios:

- Facultad de usar el logo Punto Verde en los envases de los productos

- Acceso a nuevos mercados, atrae inversionistas y fuentes de financiamiento

- Mejora el control de costos con menor uso de materias primas, agua y energía

- Aumenta la motivación de los empleados y el conocimiento de los procesos 
- Reduce los impactos ambientales a lo largo del ciclo de vida del producto

\section{Estudio del Marco Metodológico}

El principal objetivo en éste estudio fue conocer si la creación de un Restaurante Sustentable tendría la aceptación adecuada en el Km. 2 General Villamil Playas.

Tipos y Técnicas de Investigación

La investigación utilizada fue de tipo exploratoria y descriptiva mediante el cual se hicieron uso de las siguientes técnicas: observación, fuentes bibliográficas.

\section{Población y Muestra}

La población objetivo fueron hombres y mujeres residentes y turistas del cantón Gral. Villamil Playas en la Prov. Del Guayas, de toda edad tomando en cuenta su poder de compra. Según datos del INEC la población actual del Cantón Playas es de 41,935 personas repartidas en 20,693 mujeres y 21,242 hombres.

El sistema de muestreo utilizado fue el de Spiegel and Stephens (2005) considerando que se conoce el tamaño de la población. Se estima un error muestral del 5\% y una probabilidad de ocurrencia del 50\%. Despejando la fórmula la muestra, se obtuvo como resultado la realización de 380 encuestas a los habitantes del sector.

$$
n=\frac{\mathrm{N} * \mathrm{Z}^{2} * \mathrm{p} * \mathrm{q}}{\mathrm{e}^{2} *(\mathrm{~N}-1)+\mathrm{Z}^{2} * \mathrm{p} * \mathrm{q}}
$$

Se escogió utilizar la encuesta como un instrumento para poder recopilar y analizar los diferentes gustos y preferencias de los habitantes del sector, para luego aplicarlo en el modelo de negocio que se decidió a ejecutar.

Los datos obtenidos en la realización de las encuestas permitieron obtener la siguiente información:

- $\quad$ El 77\% de las personas acostumbra a salir a restaurantes.

- El 35\% de los encuestados asisten una vez por semana, el 25\% corresponde a una vez al mes, el $23 \%$ concurre una vez cada quince días y un $17 \%$ asiste diariamente.

- El 36\% de las personas acuden a un restaurante en el horario de 20:00 horas en adelante, mientras que el 28\% asiste de 18:00 a 20:00 horas, el 23\% corresponde de 12:00 a 15:00 horas, el 11\% visita de 15:00 a 18:00 y un 2\% de 9:00 a 12:00.

- El 49\% de la muestra asiste a dichos lugares en familia, mientras que el $40 \%$ acude con amigos o compañeros y el $11 \%$ restante visita solo un restaurante.

- El 70\% de los encuestados consideran la ubicación, precio, higiene, ambiente y servicio al cliente como características importantes al momento de elegir un restaurante.

- El $67 \%$ de las personas se encuentran satisfechos con los restaurantes que se encuentran en el sector. 
- El conocimiento acerca del término sustentable (ecológico) entre los encuestados, corresponde el $72 \%$.

- El 98\% de las personas consideran que sí deberían existir más restaurantes sustentables y adicionalmente en el mismo porcentaje estarían dispuestos a visitarlo.

- El 96\% les parece agradable la idea de servirse alimentos frescos libres de químicos y recién cosechados. El restante les parece indiferente.

- En el caso de una posible implementación de un restaurante sustentable, el 29\% le llama la atención el huerto orgánico, mientras que el $28 \%$ le gusta la cocina al aire libre, al $18 \%$ le agrada lo del reciclaje, el 14\% corresponde al manejo de desperdicio y solo al $11 \%$ les atrae los paneles solares.

- En relación a los servicios adicionales que le gustaría encontrar en un restaurante, el $49 \%$ les gustaría contar con un servicio de música en vivo, mientras que el 30\% le llama la atención el servicio de bar y $21 \%$ le atrae el karaoke.

- El 54\% de las personas están dispuestos a pagar entre \$5 a \$10 dólares por un plato, mientras que un 35\% pagaría de \$11 a \$15 dólares y el 11\% pagaría de \$16 dólares o más.

- El $46 \%$ de los encuestados desean recibir publicidad por redes sociales, el $25 \%$ prefiere la televisión, el $11 \%$ escogió periódicos, el $9 \%$ prefiere volantes y por último radio $5 \%$ y vallas el $4 \%$.

- Al preguntar que le atrae más en una publicidad, el $31 \%$ mencionó las promociones, el $25 \%$ prefieren descuentos, y gráficos y precios tienen el $22 \%$ respectivamente.

\section{Análisis Situacional}

El análisis situacional ayuda a realizar un examen detallado de los factores internos (fortalezas y debilidades) y los factores externos (oportunidades y amenazas) que afectan positiva o negativamente un negocio. Ayuda al empresario a obtener una visión panorámica de su negocio y diseñar las estrategias adecuadas que le permitan maximizar el valor de su empresa.

\section{$\underline{\text { Análisis Situacional PESTA }}$}

Con el análisis PESTA, introducida en 1968 por los académicos Liam Fahey y V.K. Narayanan, se logró realizar el diagnóstico externo determinando las oportunidades y amenazas del negocio en el ámbito político, económico, social, tecnológico y ambiental.

- Político-Legal: El Gobierno se ha encargado de fortalecer el turismo utilizando diferentes estrategias para darlo a conocer tanto nacional e internacionalmente, uno de sus programas conocidos "All you need is Ecuador", ha logrado un gran impacto por la gran afluencia de turistas extranjero al país. Segura (2016), concluye que De los resultados de la encuesta se puede resaltar que el $48 \%$ de las personas que visitaron el país llegaron a conocer la campaña.

- Económico: La economía del Ecuador es negativa, según información del Banco Central, el Producto Interno Bruto (PIB) 2016 se ubicó en -1,5\% originado principalmente por la caída en los precios del petróleo, la apreciación del dólar y el terremoto del 16 de abril del año pasado. El 2017 se prevé como un año de retos para todas las empresas- El sector de alimentos y bebidas es uno de los pilares más importantes en la actividad económica 
del país. Según INEC (2012), el 36,9\% de los establecimientos que existen en el país se dedican al área de alimentos y bebidas, de los cuales un 5,4\% está ligado a la elaboración de productos alimenticios, el 68,4\% se dedica al comercio al por mayor y menor y el $26,22 \%$. Por otro lado, a nivel provincial la mayor actividad económica en el área de establecimientos de alimentos y bebidas se encuentra en las provincias de: Guayas con 24,7\%, Pichincha con 19,5\% y Manabí con 7,5\%.

- Sociocultural: Las personas destinan sus gastos especialmente en productos alimenticios y de bebidas así lo determina el INEC (2012), los gastos destinados a éste rubro representan el mayor porcentaje $(24,4 \%)$; en orden de importancia, se sitúa: transporte con el 14,6\%; bienes y servicios diversos con el 9,9\%; prendas de vestir y calzado; restaurantes y hoteles, que giran alrededor del 8\%; entre los más representativos.

- Tecnológico: En Ecuador el 17,11\% de la población mayor de 5 años, es decir 2,8 millones de ecuatorianos, declara usar redes sociales a través de su teléfono inteligente, según datos del INEC; esto representaría una oportunidad para el negocio de utilizar las redes sociales como su medio de comunicación más importante para sus estrategias de marketing.

- Ambiental: En la última década se ha visto el compromiso del Gobierno con el medio ambiente, donde ha creado leyes para regular y controlar los impactos que producen las empresas al momento de sus operaciones y su impacto con la naturaleza.

\section{$\underline{\text { Análisis Situacional: Fuerzas Competitivas }}$}

El desarrollo de las 5 Fuerzas Competitivas, herramienta organizacional desarrollada por Michael Porter, permitió realizar un diagnóstico del Sector de Alimentos y Bebidas y específicamente en el área de los Restaurantes con el fin de identificar a la competencia actual y potencial, evaluando sus productos y servicios y su poder en el mercado. El desarrollo de una estrategia competitiva permitirá al negocio maximizar sus recursos y superar las acciones de la competencia.

- Poder Negociador de los Clientes: Es bajo debido a las características novedosas del proyecto, en la actualidad se encuentran pequeñas propuestas de esta índole. En el mercado será evidente la diferencia del servicio que se ofrecerá, puesto que por la existencia de varios restaurantes ninguna cuenta con las cualidades especiales y este será preferido dependiendo de las necesidades del consumidor, además el precio va acorde al nivel socio económico.

- Poder Negociador de los Proveedores: Los proveedores son una parte primordial para el impulso del proyecto, de esta forma se buscaría hacer negocio con pequeños agricultores que se encargarían de la avicultura y ganadería artesanal para que nos puedan abastecer continuamente de la materia prima necesaria, como el proyecto propuesto está enfocado en buenas prácticas con el medio ambiente, se procederá a realizar constantes visitas para así garantizar el control y cumplimiento de la exigencias de no utilizar químicos, hormonas y fertilizantes en los productos.

- Amenaza de nuevos competidores: Hoy en día la actividad turística crece enormemente y a su vez aumentan las posibilidades de que surjan nuevos competidores con ideas innovadoras. Este proyecto es atractivo, renovador y único dentro de este cantón, porque ofrecerá comida orgánica aparte de ser eco amigables con la naturaleza, los restaurantes 
aledaños querrán incursionar en este nuevo método de trabajo y se darán cuenta que puede generar ingresos sin un costo elevado en sus platos. Se debe tomar muy en cuenta que este modelo de negocio será una amenaza alta para los restaurantes que se ubican alrededor, porque ofrece algo totalmente distinto ya que la mayoría de estos negocios se dedican a vender platos típicos con mariscos de la zona. Para ello la fidelización de los clientes es muy importante. Una de las estrategias para lograr esto es ofrecer un buen servicio, ambiente y producto, así los gastos en publicidad serán bajos y la mejor difusión para promocionar el restaurante será de boca en boca a través de nuestros clientes.

- Amenaza de productos sustitutos: Como productos sustitos se considerará todo aquello que satisfaga la misma necesidad. En nuestro alrededor existe variedad de negocios que ofrecen productos sustitutos, desde una carreta informal hasta una franquicia en el centro comercial, aunque no tengan el mismo modelo de negocio, pero si tiene la capacidad de satisfacer la necesidad de alimentarse.

- Rivalidad entre empresas: La competitividad para nosotros se dará con todo negocio que brinde servicios de alimentación a un mismo mercado objetivo, en este caso los primordiales competidores serían los restaurantes o cevicheras que manejan precios estándares para los oriundos y turistas que pernoctan en este balneario turístico.

\section{$\underline{\text { Análisis Situacional: FODA }}$}

El análisis externo e interno permitió construir el FODA con la identificación de:

- Fortalezas: Idea innovadora, proveedores con compromiso con el medio ambiente, materias primas sin químicos, orgánicos, aceptación de la idea en el sector Playas mediante la realización de un estudio de mercado, prácticas ambientales en el tratamiento de los residuos, personal comprometido con la implementación del negocio.

- Oportunidades: Tendencia de los consumidores a buscar nuevas experiencias y sensaciones en la comida, crecimiento rápido del mercado, las modas favorecen a éste tipo de negocios generando una mayor afluencia de clientes.

- Debilidades: Falta de experiencia del personal al ser una empresa nueva, poca capacidad económica.

- Amenazas: Cambio en las políticas gubernamentales, aparición de nuevos competidores que ofrezcan similares productos, cambio de las condiciones de comercialización de la materia prima con los proveedores.

Estudio Técnico y Administrativo

\section{$\underline{\text { Permisos y Requisitos }}$}

Según la Ley de Compañías, La Compañía de Responsabilidad Limitada, es aquella que se contrae con dos a quince personas, con un mínimo de capital de 400 USD. Los socios solamente pueden responder a sus obligaciones hasta el monto de sus aportaciones individuales, y hacen el comercio bajo una Razón Social o denominación objetiva, a la que se le añadirá las palabras "Compañía Limitada", o en su defecto, la abreviatura Cía. Ltda. En éste caso, el nombre de la compañía será KAWSAY S.A. 
Para la creación y funcionamiento de un negocio es necesario obtener permisos y autorizaciones, que permitan operar adecuadamente, dichos requisitos son:

- Registro único de contribuyentes (RUC).

- Contrato de suministro de energía eléctrica.

- Permiso cuerpo de bomberos.

- Solicitud de búsqueda fonética (IEPI)

- Certificado del ministerio de turismo.

- Certificado de trampa grasa.

\section{$\underline{\text { Localización }}$}

El Restaurante KAWSAY estará ubicado en la Provincia del Guayas, en el Cantón Villamil Playas en la vía a Data Posorja. El terreno elegido para la construcción del local está ubicado en el km 2 de la vía a Data Posorja en la avenida principal.

\section{Equipo de Trabajo}

El negocio contempla iniciar sus operaciones con 11 personas. Entre ellas: Gerente, Administrador, Cajero, Stewart, personal de limpieza, guardia, contador, 2 Meseros, 2 cocineros.

Tabla 1. Listado del personal

\begin{tabular}{lcrr}
\hline PERSONAL & CANTIDADES & \multicolumn{1}{c}{ SUELDO } & \multicolumn{1}{c}{ TOTAL } \\
\hline Gerente & 1 & $\$ 1.200,00$ & $\$ 1.200,00$ \\
Administrador & 1 & $\$ 600,00$ & $\$ 600,00$ \\
Cajero & 1 & $\$ 450,00$ & $\$ 450,00$ \\
Mesero & 2 & $\$ 450,00$ & $\$ 900,00$ \\
Cocineros & 2 & $\$ 450,00$ & $\$ 900,00$ \\
Stewart & 1 & $\$ 380,00$ & $\$ 380,00$ \\
Limpieza & 1 & $\$ 380,00$ & $\$ 380,00$ \\
Guardia & 1 & $\$ 450,00$ & $\$ 450,00$ \\
Contador & 1 & $\$ 400,00$ & $\$ 400,00$ \\
TOTAL & 11 & & $\$ 5.660,00$ \\
\hline
\end{tabular}

Fuente: Elaboración Propia

El organigrama permitirá identificar las líneas de mando de cada colaborador dentro del negocio.

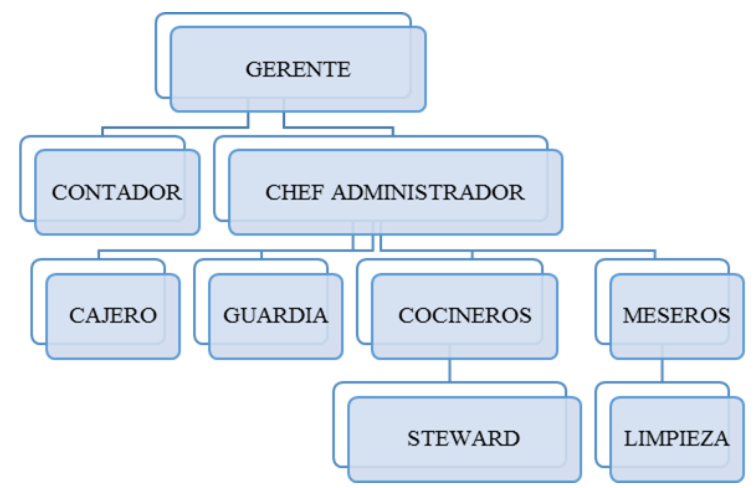

Figura 1. Organigrama 
Fuente: Elaboración Propia

$\underline{\text { Segmentación de Mercado }}$

\section{Estudio de Mercado}

La segmentación de mercado se realizó en función de los siguientes criterios:

Tabla 2. Segmentación del Mercado

\begin{tabular}{ccc}
\hline Demográfica & Edad & 17 A 60 AÑOS \\
& Sexo & Masculino y Femenino \\
Geográfica & Región & Residentes y turistas \\
& Nivel Socioeconómico & Medio bajo, medio y medio alto \\
Psicográfica & Perfil & Personas que estén dispuesto a comer saludable
\end{tabular}

Fuente: Elaboración Propia

$\underline{\text { Marketing Mix }}$

- Productos: Platos para almuerzo y cena con ingredientes orgánicos.

- Precios: Para la fijación del precio se tomaron en cuenta dos factores importantes que son: precios de la competencia y los resultados del estudio de mercado. El precio es acorde a los productos y es accesible para las personas de un nivel económico medio bajo, medio y medio alto. Los precios van desde los $\$ 4$ hasta los \$10.

- Plaza: La plaza será el sector de la vía a Data en el Cantón Playas. El único canal de distribución es la compra en el propio local.

- Promoción: Para que KAWSAY se dé a conocer se aprovecharán las redes sociales, según los estudios realizados son las más usadas por los futuros consumidores, además se realizará la entrega de volantes a los habitantes y turistas.

- Place: (evidencia física): La decoración será de tipo ecológica, se utilizarán materiales reciclados tanto para la ambientación como para la vajilla para los comensales.

- Personas: Son 11 personas que están declaradas dentro del organigrama.

- Procesos: Para la elaboración de los productos se tomará la materia prima cultivada del huerto orgánico que se creará en las instalaciones del negocio, el pescado y mariscos serán frescos de la pesca diaria que se realizan por el sector y la otra parte de insumos buscaremos proveedores que cumplan con nuestros requerimientos. Se tendrá también procesos para medir la satisfacción de los clientes, y para la atención de quejas y reclamos.

\section{$\underline{\text { Inversión Inicial }}$}

\section{Estudio Financiero}

Para la inversión inicial se consideraron todos los elementos necesarios que la empresa requiere para iniciar sus operaciones tales como: activos fijos, gastos intangibles, capital de trabajo. El monto total de la inversión ascendió a \$ 66.073,08.

Tabla 3. Inversión Inicial

\begin{tabular}{crrr}
\hline DESCRIPCIÓN & CANTIDAD & V. UNITARIO & V. TOTAL \\
\hline Capital de trabajo & 1 & $\$ 24.727,08$ & $\$ 24.727,08$ \\
\hline
\end{tabular}




\begin{tabular}{|c|c|c|c|}
\hline Imprevistos & 1 & $\$ 1.000,00$ & $\$ 1.000,00$ \\
\hline TOTAL EFECTIVO & & & $\$ 25.727,08$ \\
\hline TERRENO & CANTIDAD & V. UNITARIO & V. TOTAL \\
\hline Terreno & 250 & $\$ 30,00$ & $\$ 7.500,00$ \\
\hline TOTAL TERRENO & & & $\$ 7.500,00$ \\
\hline EDIFICIO & CANTIDAD & V. UNITARIO & V. TOTAL \\
\hline Construcción del local & 220 & $\$ 70,00$ & $\$ 15.400,00$ \\
\hline Adecuación del local & 220 & $\$ 20,00$ & $\$ 4.400,00$ \\
\hline TOTAL EDIFICIO & & & $\$ 19.800,00$ \\
\hline EQUIPOS Y UTENSILIOS & CANTIDAD & V. UNITARIO & V. TOTAL \\
\hline Cocina industrial, horno & 1 & $\$ 1.200,00$ & $\$ 1.200,00$ \\
\hline Congelador, enfriador & 1 & $\$ 1.400,00$ & $\$ 1.400,00$ \\
\hline Mesa acero inoxidable & 2 & $\$ 390,00$ & $\$ 780,00$ \\
\hline Lavabo 2 pozos & 1 & $\$ 450,00$ & $\$ 450,00$ \\
\hline Ollas y sartenes & 10 & $\$ 25,00$ & $\$ 250,00$ \\
\hline Enfriador de bebidas & 1 & $\$ 750,00$ & $\$ 750,00$ \\
\hline Licuadora & 1 & $\$ 80,00$ & $\$ 80,00$ \\
\hline Batidora & 1 & $\$ 80,00$ & $\$ 80,00$ \\
\hline Cucharetas & 10 & $\$ 3,00$ & $\$ 30,00$ \\
\hline Colador & 1 & $\$ 6,00$ & $\$ 6,00$ \\
\hline Exprimidor & 1 & $\$ 30,00$ & $\$ 30,00$ \\
\hline Cuchillo Cebollero $12 \mathrm{~cm}$ & 2 & $\$ 15,00$ & $\$ 30,00$ \\
\hline Extintores & 2 & $\$ 50,00$ & $\$ 100,00$ \\
\hline Balanza digital & 1 & $\$ 75,00$ & $\$ 75,00$ \\
\hline Microondas & 1 & $\$ 150,00$ & $\$ 150,00$ \\
\hline Tablas & 2 & $\$ 15,00$ & $\$ 30,00$ \\
\hline Trampa de grasa & 1 & $\$ 150,00$ & $\$ 150,00$ \\
\hline Extractor de grasa & 1 & $\$ 250,00$ & $\$ 250,00$ \\
\hline TOTAL EQUIPOS Y UTENSILIOS & & & $\$ 5.841,00$ \\
\hline MUEBLES Y ENSERES SALON & CANTIDAD & V. UNITARIO & V. TOTAL \\
\hline Mesas & 10 & $\$ 60,00$ & $\$ 600,00$ \\
\hline Sillas & 40 & $\$ 25,00$ & $\$ 1.000,00$ \\
\hline Mueble Bar & 1 & $\$ 200,00$ & $\$ 200,00$ \\
\hline Aparador de platos & 1 & $\$ 200,00$ & $\$ 200,00$ \\
\hline Individuales Bambú & 40 & $\$ 2,00$ & $\$ 80,00$ \\
\hline Servilleteros & 10 & $\$ 3,00$ & $\$ 30,00$ \\
\hline Vajillas & 100 & $\$ 4,00$ & $\$ 400,00$ \\
\hline Cubertería & 100 & $\$ 0,60$ & $\$ 60,00$ \\
\hline Cristalería & 100 & $\$ 0,60$ & $\$ 60,00$ \\
\hline Luminarias & 10 & $\$ 20,00$ & $\$ 200,00$ \\
\hline TOTAL MUEBLES Y ENSERES & & & $\$ 2.830,00$ \\
\hline EQUIPOS DE OFICINA & CANTIDAD & V. UNITARIO & V. TOTAL \\
\hline Plasma 42" & 1 & $\$ 600,00$ & $\$ 600,00$ \\
\hline Equipo de audio & 1 & $\$ 250,00$ & $\$ 250,00$ \\
\hline Teléfono & 1 & $\$ 35,00$ & $\$ 35,00$ \\
\hline Escritorio y silla para caja & 1 & $\$ 200,00$ & $\$ 200,00$ \\
\hline TOTAL EQUIPOS DE OFICINA & & & $\$ 1.085,00$ \\
\hline EQUIPO DE COMPUTACION & CANTIDAD & V. UNITARIO & V. TOTAL \\
\hline Impresora matricial & 1 & $\$ 90,00$ & $\$ 90,00$ \\
\hline Computadora + Software & 1 & $\$ 1.200,00$ & $\$ 1.200,00$ \\
\hline \multicolumn{3}{|l|}{ TOTAL EQUIPOS DE COMPUTACION } & $\$ 1.290,00$ \\
\hline GASTOS DE CONSTITUCION & CANTIDAD & V. UNITARIO & V. TOTAL \\
\hline Planos & 1 & $\$ 500,00$ & $\$ 500,00$ \\
\hline Tasas y permisos & 1 & $\$ 1.000,00$ & $\$ 1.000,00$ \\
\hline Consultoría técnica & 1 & $\$ 500,00$ & $\$ 500,00$ \\
\hline TOTAL GASTOS DE CONSTITUCIC & ON & & $\$ 2.000,00$ \\
\hline
\end{tabular}




\begin{tabular}{lll}
\hline TOTAL DE INVERSIÓN & \$66.073,08 \\
\hline & Fuente: Elaboración Propia
\end{tabular}

\section{$\underline{\text { Financiamiento }}$}

Para financiar la inversión requerida, se estimó el aporte de socios en un $25 \%$ (\$16,518.27); la diferencia $\$ 49.554,81$ se proyectó canalizarla a través de un crédito con la $\mathrm{CFN}$ a 5 años a una tasa del $9,8 \%$ anual.

Tabla 4. Crédito Bancario

\begin{tabular}{lr}
\hline \multicolumn{1}{c}{ CONCEPTO } & \multicolumn{1}{c}{ VALOR } \\
\hline Monto & $\$ 49.554,81$ \\
Tasa de interés anual & $9,8 \%$ \\
Plazo & 5 AÑOS/ 60 MESES \\
Cuota anual & $\$ 9.910,96$ \\
Cuota mensual & $\$ 825,91$ \\
\hline
\end{tabular}

Fuente: Elaboración Propia

\section{$\underline{\text { Balance de Situación Inicial }}$}

Parte de éstos activos del negocio serán financiados a través de deuda en un $75 \%$, y el restante con capital propio aportado por los socios. En el balance inicial se muestran las cuentas de activos, pasivo y patrimonio.

Tabla 5. Balance Inicial

Balance Inicial

KAWSAY S.A.

Al 1 de Octubre del 2017

\begin{tabular}{|c|c|c|c|c|}
\hline ACTIVOS & & & PASIVO & \\
\hline ACTIVO CORRIE & & & $\begin{array}{l}\text { PASIVO } \\
\text { CORRIENTE }\end{array}$ & \\
\hline Caja & $\begin{array}{r}\$ \\
25.727,08\end{array}$ & & $\begin{array}{lr}\text { Documentos x pagar } & \$ \\
& 49.554,81\end{array}$ & \\
\hline TOTAL ACTI & RRIENTE & $\begin{array}{r}\$ \\
25.727,08\end{array}$ & TOTAL PASIVO CORRIENTE & $\begin{array}{r}\$ \\
49.554,81\end{array}$ \\
\hline ACTIVO FIJO & & & & \\
\hline Terreno & $\$ 7.500,00$ & & TOTAL PASIVOS & $\begin{array}{r}\$ \\
49.554,81\end{array}$ \\
\hline Edificio & $\begin{array}{r}\$ \\
19.800,00\end{array}$ & & PATRIMONIO & \\
\hline Muebles y enseres & $\$ 2.830,00$ & & $\begin{array}{lr}\text { Capital Social } & \$ \\
& 16.518,27\end{array}$ & \\
\hline Equipos de cocina & $\$ 5.841,00$ & & TOTAL PATRIMONIO & $\begin{array}{r}\$ \\
16.518,27\end{array}$ \\
\hline $\begin{array}{l}\text { Equipos de } \\
\text { computación }\end{array}$ & $\$ 1.290,00$ & & & \\
\hline Equipos de oficina & $\$ 1.085,00$ & & & \\
\hline $\begin{array}{r}\text { TOTA } \\
\text { ACTIVO DIFERII }\end{array}$ & IIVO FIJO & $\begin{array}{r}\$ \\
38.346,00\end{array}$ & & \\
\hline
\end{tabular}




\author{
Gastos de \\ Constitución
}

TOTAL ACTIVO DIFERIDO
$\$ 2.000,00$

\begin{tabular}{rrr}
$\$$ & TOTAL PASIVO + PATROMONIO & $\$$ \\
$66.073,08$ & & $66.073,08$ \\
\hline
\end{tabular}

Fuente: Elaboración Propia

\section{$\underline{\text { Presupuesto de Ingresos }}$}

El presupuesto de ingresos está conformado por el volumen de ventas diarias, los precios (incluido el margen de beneficio) de cada plato y el valor de la venta anual en dólares. El cálculo se hizo teniendo una capacidad instalada para 40 personas en el almuerzo y 40 en la cena, teniendo una capacidad utilizada del 100 y $50 \%$ respectivamente.

Tabla 6. Ingresos por Ventas

\begin{tabular}{lccrrr}
\hline PRODUCTO & $\begin{array}{c}\text { PRECI } \\
\mathrm{O}\end{array}$ & $\begin{array}{c}\text { UNIDAD } \\
\text { DIARIA }\end{array}$ & $\begin{array}{c}\text { VENTA } \\
\text { DIARIA }\end{array}$ & \multicolumn{1}{c}{$\begin{array}{c}\text { VENTA } \\
\text { MENSUAL }\end{array}$} & \multicolumn{1}{c}{ VENTA } \\
\hline $\begin{array}{l}\text { Almuerzo } \\
\text { ejecutivo }\end{array}$ & $\$ 4,00$ & 40 & $\$ 160,00$ & $\$ 4.800,00$ & $\$ 57.600,00$ \\
$\quad \begin{array}{l}\text { Platos a la carta } \\
\text { Piqueos }\end{array}$ & $\$ 7,50$ & 20 & $\$ 150,00$ & $\$ 4.500,00$ & $\$ 54.000,00$ \\
Postres & $\$ 3,50$ & 10 & $\$ 35,00$ & $\$ 1.050,00$ & $\$ 12.600,00$ \\
Colas & $\$ 3,50$ & 10 & $\$ 35,00$ & $\$ 1.050,00$ & $\$ 12.600,00$ \\
Jugos & $\$ 1,00$ & 20 & $\$ 20,00$ & $\$ 600,00$ & $\$ 7.200,00$ \\
Aguas & $\$ 1,50$ & 20 & $\$ 30,00$ & $\$ 900,00$ & $\$ 10.800,00$ \\
Cervezas & $\$ 1,50$ & 10 & $\$ 20,00$ & $\$ 600,00$ & $\$ 7.200,00$ \\
TOTAL DE INGRESOS & & $\$ 15,00$ & $\$ 450,00$ & $\$ 5.400,00$ \\
\hline
\end{tabular}

Fuente: Elaboración Propia

A partir del año 2 para la proyección de ingresos se considerará una tasa de inflación del $3,01 \%$ para los siguientes años.

Tabla 7. Proyección de Ingresos

\begin{tabular}{lrrrrr}
\hline \multicolumn{1}{c}{ PRODUCTO } & \multicolumn{1}{c}{ AÑ 1} & \multicolumn{1}{c}{ AÑO 2} & \multicolumn{1}{c}{ AÑO3 } & \multicolumn{1}{c}{ AÑ 4} & \multicolumn{1}{c}{ AÑ 5} \\
\hline Almuerzo ejecutivo & $\$ 57.600,00$ & $\$ 59.333,76$ & $\$ 61.119,71$ & $\$ 62.959,41$ & $\$ 64.854,49$ \\
Platos a la carta & $\$ 54.000,00$ & $\$ 55.625,40$ & $\$ 57.299,72$ & $\$ 59.024,45$ & $\$ 60.801,08$ \\
Piqueos & $\$ 12.600,00$ & $\$ 12.979,26$ & $\$ 13.369,94$ & $\$ 13.772,37$ & $\$ 14.186,92$ \\
Postres & $\$ 12.600,00$ & $\$ 12.979,26$ & $\$ 13.369,94$ & $\$ 13.772,37$ & $\$ 14.186,92$ \\
Colas & $\$ 7.200,00$ & $\$ 7.416,72$ & $\$ 7.639,96$ & $\$ 7.869,93$ & $\$ 8.106,81$ \\
Jugos & $\$ 10.800,00$ & $\$ 11.125,08$ & $\$ 11.459,94$ & $\$ 11.804,89$ & $\$ 12.160,22$ \\
Aguas & $\$ 7.200,00$ & $\$ 7.416,72$ & $\$ 7.639,96$ & $\$ 7.869,93$ & $\$ 8.106,81$ \\
Cervezas & $\$ 5.400,00$ & $\$ 5.562,54$ & $\$ 5.729,97$ & $\$ 5.902,44$ & $\$ 6.080,11$ \\
TOTAL DE & $\$$ & $\$$ & $\$$ & $\$$ & $\$$ \\
INGRESOS & $167.400,00$ & $172.438,74$ & $177.629,15$ & $182.975,78$ & $188.483,35$ \\
\hline
\end{tabular}

Fuente: Elaboración Propia

Presupuesto de Gastos 
En este presupuesto se detallan todos los rubros de materia prima directa, mano de obra directa, gastos indirectos de fabricación, gastos de administración, gastos de ventas y gastos financieros. Para proyectar los siguientes años se considera la tasa de inflación del Ecuador de los últimos 5 años, se realiza un promedio y con ello se elabora el presupuesto de costos y gastos.

Tabla 8. Presupuestos Costos y Gastos

\begin{tabular}{|c|c|}
\hline \multicolumn{2}{|l|}{ COSTOS DE PRODUCCION } \\
\hline \multicolumn{2}{|l|}{ COSTOS DIRECTOS } \\
\hline Mano de Obra Directa & $\$ 35.265,50$ \\
\hline Materia Prima Directa & $\$ 53.640,00$ \\
\hline SUBTOTAL & $\$ 88.905,50$ \\
\hline \multicolumn{2}{|l|}{ COSTOS INDIRECTOS DE FABRICACION } \\
\hline Mano de Obra Indirecta & $\$ 28.360,78$ \\
\hline Materiales Indirectos & $\$ 465,30$ \\
\hline Suministro de Limpieza & $\$ 727,34$ \\
\hline Servicios Básicos & $\$ 2.825,76$ \\
\hline Depreciación Activos Fijos & $\$ 1.857,10$ \\
\hline SUBTOTAL & $\$ 34.236,28$ \\
\hline \multicolumn{2}{|l|}{ GASTOS ADMINISTRATIVOS } \\
\hline Sueldos Personal Administrativos & $\$ 19.381,12$ \\
\hline Contador & $\$ 6.711,04$ \\
\hline Suministros de Oficina & $\$ 326,83$ \\
\hline Implementación del Plan de Marketing & $\$ 658,80$ \\
\hline Depreciación Activos Fijos & $\$ 647,00$ \\
\hline Amortización Activos Diferidos & $\$ 400,00$ \\
\hline SUBTOTAL & $\$ 28.124,79$ \\
\hline TOTAL & $\$ 151.266,57$ \\
\hline
\end{tabular}

Fuente: Elaboración Propia

\section{Estado de Pérdidas y Ganancias Proyectado}

En el Estado de pérdidas y ganancias luego de haber analizado los ingresos y los costos de la empresa se pudo determinar que hay utilidad neta positiva durante todos los años.

Tabla 9. Estado de Pérdidas y Ganancias Proyectado

$$
\text { ESTADO DE PERDIDAS Y GANANCIAS }
$$

\section{KAWSAY S.A.}

\begin{tabular}{lrrrrr}
\multicolumn{1}{c}{ Al 31 de Diciembre 2018 } & & & \\
\hline & AÑO 1 & AÑO 2 & AÑO 3 & AÑO 4 & \multicolumn{1}{c}{ AÑO 5 } \\
INGRESO POR VENTAS & $\$$ & $\$$ & $\$$ & $\$$ & $\$$ \\
& $167.400,00$ & $172.438,74$ & $177.629,15$ & $182.975,78$ & $188.483,35$ \\
(-) COSTO DE PRODUCCION & $\$$ & $\$$ & $\$$ & $\$$ & $\$$ \\
COSTOS DIRECTOS & $123.141,78$ & $126.848,35$ & $130.666,48$ & $134.599,54$ & $138.650,99$ \\
Materia Prima Directa & & & & & \\
& $\$$ & $\$$ & $\$$ & $\$$ & $\$$ \\
\hline
\end{tabular}




\begin{tabular}{|c|c|c|c|c|c|}
\hline \multirow[t]{2}{*}{ Mano de Obra Directa } & $\$$ & $\$$ & $\$$ & $\$$ & $\$$ \\
\hline & $35.265,50$ & $36.326,99$ & $37.420,43$ & $38.546,79$ & $39.707,05$ \\
\hline \multirow{2}{*}{ TOTAL } & $\$$ & $\$$ & $\$$ & $\$$ & $\$$ \\
\hline & $88.905,50$ & $91.581,56$ & $94.338,16$ & $97.177,74$ & $100.102,79$ \\
\hline \multicolumn{6}{|l|}{ COSTOS INDIRECTOS } \\
\hline \multirow[t]{2}{*}{ Mano de Obra Indirecta } & $\$$ & $\$$ & $\$$ & $\$$ & $\$$ \\
\hline & $28.360,78$ & $29.214,44$ & $30.093,79$ & $30.999,62$ & $31.932,71$ \\
\hline Materiales Indirectos & $\$ 465,30$ & $\$ 479,31$ & $\$ 493,73$ & $\$ 508,59$ & $\$ 523,90$ \\
\hline Suministro de Limpieza & $\$ 727,34$ & $\$ 749,23$ & $\$ 771,78$ & $\$ 795,02$ & $\$ 818,95$ \\
\hline \multirow[t]{2}{*}{ Servicios Básicos } & $\$$ & $\$$ & $\$$ & $\$$ & $\$$ \\
\hline & $2.825,76$ & $2.910,82$ & $2.998,43$ & $3.088,68$ & $3.181,65$ \\
\hline \multirow[t]{2}{*}{ Depreciación Activos Fijos } & $\$$ & $\$$ & $\$$ & $\$$ & $\$$ \\
\hline & $1.857,10$ & $1.913,00$ & $1.970,58$ & $2.029,89$ & $2.090,99$ \\
\hline \multirow[t]{2}{*}{ TOTAL } & $\$$ & $\$$ & $\$$ & $\$$ & $\$$ \\
\hline & $34.236,28$ & $35.266,79$ & $36.328,32$ & $37.421,80$ & $38.548,20$ \\
\hline \multirow[t]{2}{*}{ UTILIDAD BRUTA OPERACIONAL } & $\$$ & $\$$ & $\$$ & $\$$ & $\$$ \\
\hline & $44.258,22$ & $45.590,39$ & $46.962,66$ & $48.376,24$ & $49.832,36$ \\
\hline \multirow[t]{2}{*}{ (-) GASTOS OPERACIONALES } & $\$$ & $\$$ & $\$$ & $\$$ & $\$$ \\
\hline & $28.124,79$ & $28.971,35$ & $29.843,38$ & $30.741,67$ & $31.666,99$ \\
\hline \multirow[t]{2}{*}{ Sueldos Personal Administrativos } & $\$$ & $\$$ & $\$$ & $\$$ & $\$$ \\
\hline & $19.381,12$ & $19.964,49$ & $20.565,42$ & $21.184,44$ & $21.822,09$ \\
\hline \multirow[t]{2}{*}{ Contador } & $\$$ & $\$$ & $\$$ & $\$$ & $\$$ \\
\hline & $6.711,04$ & $6.913,04$ & $7.121,12$ & $7.335,47$ & $7.556,27$ \\
\hline Suministros de Oficina & $\$ 326,83$ & $\$ 336,67$ & $\$ 346,80$ & $\$ 357,24$ & $\$ 367,99$ \\
\hline Implementación del Plan de Marketing & $\$ 658,80$ & $\$ 678,63$ & $\$ 699,06$ & $\$ 720,10$ & $\$ 741,77$ \\
\hline Depreciación Activos Fijos & $\$ 647,00$ & $\$ 666,47$ & $\$ 686,54$ & $\$ 707,20$ & $\$ 728,49$ \\
\hline Amortización Activos Diferidos & $\$ 400,00$ & $\$ 412,04$ & $\$ 424,44$ & $\$ 437,22$ & $\$ 450,38$ \\
\hline \multirow[t]{2}{*}{ TOTAL } & $\$$ & $\$$ & $\$$ & $\$$ & $\$$ \\
\hline & $28.124,79$ & $28.971,35$ & $29.843,38$ & $30.741,67$ & $31.666,99$ \\
\hline \multirow[t]{2}{*}{ UTILIDAD OPERACIONAL } & $\$$ & $\$$ & $\$$ & $\$$ & $\$$ \\
\hline & $16.133,43$ & $16.619,05$ & $17.119,28$ & $17.634,57$ & $18.165,37$ \\
\hline \multicolumn{6}{|l|}{ (-) GASTOS FINANCIEROS } \\
\hline \multirow[t]{2}{*}{ Interés de la deuda } & $\$$ & $\$$ & $\$$ & $\$$ & $\$$ \\
\hline & $4.532,61$ & $3.787,22$ & $2.968,78$ & $2.070,13$ & $1.083,41$ \\
\hline UTILIDAD ANTES DE & $\$$ & $\$$ & $\$$ & $\$$ & $\$$ \\
\hline PARTICIPACION LABORAL & $11.600,82$ & $12.831,83$ & $14.150,50$ & $15.564,44$ & $17.081,96$ \\
\hline \multirow{2}{*}{ (-) 15\% Participación Laboral } & $\$$ & $\$$ & $\$$ & $\$$ & $\$$ \\
\hline & $1.740,12$ & $1.924,77$ & $2.122,58$ & $2.334,67$ & $2.562,29$ \\
\hline UTILIDAD ANTES DEL IMPUESTO A & $\$$ & $\$$ & $\$$ & $\$$ & $\$$ \\
\hline LA RENTA & $9.860,69$ & $10.907,05$ & $12.027,93$ & $13.229,77$ & $14.519,66$ \\
\hline \multirow[t]{2}{*}{ (-) $22 \%$ Impuesto a la Renta } & $\$$ & $\$$ & $\$$ & $\$$ & $\$$ \\
\hline & $2.169,35$ & $2.399,55$ & $2.646,14$ & $2.910,55$ & $3.194,33$ \\
\hline \multirow{2}{*}{ UTILIDAD NETA DISPONIBLE } & $\$$ & $\$$ & $\$$ & $\$$ & $\$$ \\
\hline & $7.691,34$ & $8.507,50$ & $9.381,78$ & $10.319,22$ & $11.325,34$ \\
\hline
\end{tabular}

Fuente: Elaboración Propia

\section{$\underline{\text { Flujo de Caja Proyectado }}$}

Sistematiza los costos y beneficios financieros, así como las entradas y salidas de capital ocurridos en cada período del proyecto.

Tabla 10. Flujo de Caja Proyectado 


\begin{tabular}{|c|c|c|c|c|c|c|}
\hline \multicolumn{7}{|c|}{$\begin{array}{c}\text { FLUJO DE CAJA PROYECTADO } \\
\text { KAWSAY S.A. } \\
\text { Al } 31 \text { de Diciembre } 2018\end{array}$} \\
\hline & AÑO 0 & AÑO 1 & AÑO 2 & AÑO 3 & AÑO 4 & AÑO 5 \\
\hline \multicolumn{7}{|l|}{ FLUJO DE INGRESOS } \\
\hline \multirow[t]{2}{*}{ Ventas Netas } & & $\$$ & $\$$ & $\$$ & $\$$ & $\$$ \\
\hline & & $167.400,00$ & $172.438,74$ & $177.629,15$ & $182.975,78$ & $188.483,35$ \\
\hline \multicolumn{2}{|l|}{ Recuperación Capital de } & & & & & $\$$ \\
\hline \multicolumn{2}{|l|}{ Trabajo } & & & & & $25.727,08$ \\
\hline \multicolumn{2}{|l|}{ TOTAL FLUJO DE } & $\$$ & $\$$ & $\$$ & $\$$ & $\$$ \\
\hline \multicolumn{2}{|l|}{ BENFICIOS } & $167.400,00$ & $172.438,74$ & $177.629,15$ & $182.975,78$ & $214.210,43$ \\
\hline \multicolumn{7}{|l|}{ FLUJO DE EGRESOS } \\
\hline Inversión en Activos & $\$$ & & & & & \\
\hline \multirow{2}{*}{\multicolumn{7}{|c|}{$\begin{array}{l}\text { Fijos } \\
\text { Inversión en Activos }\end{array}$}} \\
\hline & & & & & & \\
\hline \multicolumn{7}{|l|}{ Diferidos } \\
\hline \multirow[t]{2}{*}{ Capital de Trabajo } & $\$$ & & & & & \\
\hline & $25.727,08$ & & & & & \\
\hline \multirow{2}{*}{ Costos de producción } & & $\$$ & $\$$ & $\$$ & $\$$ & $\$$ \\
\hline & & $123.141,78$ & $126.848,35$ & $130.666,48$ & $134.599,54$ & $138.650,99$ \\
\hline \multirow[t]{2}{*}{ (-) Depreciaciones } & & $\$$ & $\$$ & $\$$ & $\$$ & $\$$ \\
\hline & & $2.504,10$ & $2.504,10$ & $2.504,10$ & $2.504,10$ & $2.504,10$ \\
\hline \multirow[t]{2}{*}{ Gastos Operacionales } & & $\$$ & $\$$ & $\$$ & $\$$ & $\$$ \\
\hline & & $28.124,79$ & $28.971,35$ & $29.843,38$ & $30.741,67$ & $31.666,99$ \\
\hline \multirow{3}{*}{$\begin{array}{l}\text { (-) Amortizaciones } \\
\text { Gastos Financieros }\end{array}$} & & $\$ 400,00$ & $\$ 400,00$ & $\$ 400,00$ & $\$ 400,00$ & $\$ 400,00$ \\
\hline & & $\$$ & $\$$ & $\$$ & $\$$ & $\$ 971,27$ \\
\hline & & $4.856,37$ & $3.885,10$ & $2.913,82$ & $1.942,55$ & \\
\hline TOTAL FLUIO DE & $\$$ & $\$$ & $\$$ & $\$$ & $\$$ & $\$$ \\
\hline & $66.073,08$ & $153.218,84$ & $156.800,69$ & $160.519,59$ & $164.379,66$ & $168.385,16$ \\
\hline \multirow{2}{*}{$\begin{array}{l}\text { COSTOS } \\
\text { FLUJO ECONOMICO }\end{array}$} & $-\$$ & $\$$ & $\$$ & $\$$ & $\$$ & $\$$ \\
\hline & $66.073,08$ & $14.181,16$ & $15.638,05$ & $17.109,56$ & $18.596,12$ & $45.825,27$ \\
\hline \multirow[t]{2}{*}{ (+) Préstamo } & $\$$ & & & & & \\
\hline & $49.554,81$ & & & & & \\
\hline (-) Amortización de la & & $\$$ & $\$$ & $\$$ & $\$$ & $\$$ \\
\hline Deuda & & $5.054,59$ & $6.025,86$ & $6.997,14$ & $7.968,41$ & $8.939,69$ \\
\hline (-) 15\% Participación & & $\$$ & $\$$ & $\$$ & $\$$ & $\$$ \\
\hline Laboral & & $1.691,56$ & $1.910,09$ & $2.130,82$ & $2.353,80$ & $2.579,11$ \\
\hline (-) $22 \%$ Impuesto a la & & $\$$ & $\$$ & $\$$ & $\$$ & $\$$ \\
\hline Renta & & $2.108,81$ & $2.381,25$ & $2.656,42$ & $2.934,41$ & $3.215,30$ \\
\hline TOTAL FLUJO & $-\$$ & $\$$ & $\$$ & $\$$ & $\$$ & $\$$ \\
\hline FINANCIERO & $16.518,27$ & $5.326,20$ & $5.320,84$ & $5.325,18$ & $5.339,50$ & $31.091,18$ \\
\hline
\end{tabular}

En la tabla podemos observar que en el Año cero se detalla las inversiones realizadas en Activos y Capital de trabajo obteniendo como resultado un Flujo negativo, a partir del Año 1 el restaurante empieza su actividad, por lo que se detallan los ingresos generados año tras año y los porcentajes correspondientes a la participación laboral y el impuesto a la renta quedando como resultado el Total del Flujo Financiero. Con estos valores se podrá calcular la rentabilidad del proyecto mediante el VAN, TIR, B/C entre otros.

\section{Resultados}

$\underline{\text { Tasa Mínima Aceptable de Rendimiento (TMAR) }}$ 
Es la tasa mínima aceptable de ganancia que un inversionista estaría dispuesto a aceptar al invertir en un determinado proyecto. Para realizar el TMAR primero debemos de calcular el Costo del Patrimonio (KP), de los socios y del Banco.

Tabla 11. KP Socios y KP Bancos

\begin{tabular}{|c|c|}
\hline COMPONENTES & $\%$ \\
\hline RIESGO DEL PAIS & $7,33 \%$ \\
\hline TASA PASIVA & $4,89 \%$ \\
\hline INFLACION & $3,01 \%$ \\
\hline KP SOCIOS & $15,23 \%$ \\
\hline COMPONENTES & $\%$ \\
\hline TASA ACTIVA & $9,80 \%$ \\
\hline KP BANCO & $9,80 \%$ \\
\hline
\end{tabular}

Como se puede observar el KP considera Riesgo de Inversión, Tasa Pasiva, Inflación y Tasa Activa. Para calcular el TMAR utilizaremos la siguiente formula:

$\mathrm{TMAR}=(\mathrm{KP}$ deuda $*(\%)$ relativo de la deuda $)+(\mathrm{KP}$ bancos $*(\%)$ relativo del aporte socios $)$.

Tabla 12. Calculo TMAR

\begin{tabular}{lccrr}
\hline CONCEPTO & VALOR & $\%$ & \multicolumn{1}{c}{ TASA } & \multicolumn{1}{c}{$\begin{array}{r}\text { COSTO } \\
\text { NOMINAL (KP) }\end{array}$} \\
& & & $9,80 \%$ & $7,35 \%$ \\
\hline Deuda CFN & $\$ 49.554,81$ & $75 \%$ & $15,23 \%$ & $3,81 \%$ \\
Aporte Socios & $\$ 16.518,27$ & $25 \%$ & TMAR & $11,16 \%$ \\
TOTAL & $\$ 66.073,08$ & $100 \%$ & \\
\hline
\end{tabular}

Fuente: Elaboración Propia

\section{$\underline{\text { Valor Actual Neto (VAN) }}$}

Para el cálculo del VAN es necesario emplear el TMAR calculada anteriormente, de ahí se permite calcular el valor presente, de los flujos de caja futuros. Para calcular el VAN utilizaremos la siguiente fórmula:

$$
\begin{aligned}
& \text { VAN }= \frac{F N E 1}{(1+T M A R)^{1}}+\frac{F N E 2}{(1+T M A R)^{2}}+\frac{F N E 3}{(1+T M A R)^{3}}+\frac{F N E 4}{(1+T M A R)^{4}}+\frac{F N E 5}{(1+T M A R)^{5}} \\
& \quad-I N V E R S I O N \\
& \mathrm{VAN}= \frac{14181,16}{(1+0,1116)^{1}}+\frac{15638,05}{(1+0,1116)^{2}}+\frac{17109,56}{(1+0,1116)^{3}}+\frac{18596,12}{(1+0,1116)^{4}}+\frac{45825,27}{(1+0,1116)^{5}} \\
& \quad-66073,08
\end{aligned}
$$

Tabla 13. VAN del Proyecto

\begin{tabular}{cccrr}
\hline $\begin{array}{c}\text { AÑ } \\
\text { OS }\end{array}$ & $\begin{array}{c}\text { FLUJO NETO DE } \\
\text { EFECTIVO }\end{array}$ & $\begin{array}{c}\text { TASA DE } \\
\text { DESCUENTO }\end{array}$ & $\begin{array}{c}\text { VALOR NETO } \\
\text { ACTUALIZADO }\end{array}$ & $\begin{array}{r}\text { FLUJO NETO } \\
\text { ACUMULADO }\end{array}$ \\
\hline 0 & $-\$ 66.073,08$ & $11,16 \%$ & $-\$ 66.073,08$ & $-\$ 66.073,08$ \\
1 & $\$ 14.181,16$ & $11,16 \%$ & $\$ 12.757,72$ & $-\$ 53.315,36$ \\
2 & $\$ 15.638,05$ & $11,16 \%$ & $\$ 12.656,25$ & $-\$ 40.659,11$ \\
3 & $\$ 17.109,56$ & $11,16 \%$ & $\$ 12.457,26$ & $-\$ 28.201,85$ \\
4 & $\$ 18.596,12$ & $11,16 \%$ & $\$ 12.180,56$ & $-\$ 16.021,29$ \\
\hline
\end{tabular}




\begin{tabular}{|c|c|c|c|c|}
\hline 5 & $\$ 45.825,27$ & $\begin{array}{r}11,16 \% \\
\text { VAN }\end{array}$ & $\begin{array}{l}\$ 27.002,95 \\
\$ 10.981,66\end{array}$ & \$ 10.981,66 \\
\hline
\end{tabular}

Fuente: Elaboración Propia

En la tabla podemos observar que nuestro VAN es positivo, por lo tanto, el proyecto es viable y alcanza la rentabilidad esperada. Después de 5 años de pagar las Inversiones Iniciales el negocio queda funcionando y con montos positivos a su favor.

\section{$\underline{\text { Tasa Interna de Retorno (TIR) }}$}

Es la tasa de descuento que permite poner el Valor Actual Neto en cero, a partir de este criterio podemos determinar la viabilidad del proyecto siempre y cuando la TIR sea mayor al TMAR. Para calcular el TIR utilizaremos la siguiente fórmula:

$$
\mathrm{TIR}=\operatorname{INVERSION}+\frac{F N E 1}{(1+r)^{1}}+\frac{F N E 2}{(1+r)^{2}}+\frac{F N E 3}{(1+r)^{3}}+\frac{F N E 4}{(1+r)^{4}}+\frac{F N E 5}{(1+r)^{5}}
$$

Tabla 14. TIR del Proyecto

\begin{tabular}{|c|c|}
\hline TASA DE DESCUENTO & VALOR ACTUAL NETO \\
\hline $0 \%$ & $\$ 45.277,08$ \\
\hline $5 \%$ & $\$ 27.601,21$ \\
\hline $10 \%$ & $\$ 13.752,85$ \\
\hline $11,16 \%$ & $\$ 10.981,66$ \\
\hline $15 \%$ & $\$ 2.748,44$ \\
\hline $16,441 \%$ & $\$ 0,54$ \\
\hline $20 \%$ & $(\$ 6.110,14)$ \\
\hline $25 \%$ & $(\$ 13.326,71)$ \\
\hline TIR & $16,44 \%$ \\
\hline
\end{tabular}

Fuente: Elaboración Propia

Como podemos observar en la tabla el TIR es mayor al TMAR, por lo tanto, los inversionistas obtendrán una rentabilidad mayor a la mínima deseada.

\section{$\underline{\text { Relación Costo - Beneficio }}$}

Por medio de la relación determinaremos cuantos son los beneficios que se obtienen con respecto a los costos que tiene el proyecto. Para calcular este dato se debe utilizar la siguiente fórmula:

$$
\begin{array}{r}
\text { Razon } B / C=\frac{\sum \text { Valores Actualizados }}{\text { Inversion }} \\
\text { Razon } B / C=\frac{77054,74}{66073,08}
\end{array}
$$

Tabla 15. Razón Beneficio-Costo

\begin{tabular}{rrr}
\hline AÑOS & FLUJO NETO DE EFECTIVO & VALOR NETO ACTUALIZADO \\
\hline 0 & $-\$ 66.073,08$ & \\
1 & $\$ 14.181,16$ & $\$ 12.757,72$ \\
2 & $\$ 15.638,05$ & $\$ 12.656,25$ \\
\hline
\end{tabular}




\begin{tabular}{rrr}
\hline 3 & $\$ 17.109,56$ & $\$ 12.457,26$ \\
4 & $\$ 18.596,12$ & $\$ 12.180,56$ \\
5 & $\$ 45.825,27$ & $\$ 27.002,95$ \\
& TOTAL & $\$ 77.054,74$ \\
& B/C & 1,17 \\
\hline
\end{tabular}

Fuente: Elaboración Propia

Por cada dólar invertido en el proyecto, se obtiene una ganancia de 0,17 ctvs.

\section{$\underline{\text { Período de Recuperación de la Inversión (PRI) o Payback }}$}

Determinará el tiempo exacto en el que el proyecto tarda en recuperar la inversión, en función de los flujos de caja actualizados. La fórmula a emplearse es la siguiente:

$$
\begin{gathered}
\mathrm{PRI}=(N-1)+\frac{\text { Ultima Recuperacionn Acumulada en Negativo }}{\text { FNE Posterior a la Ultim. Recup. Acum. en Negativo }} \\
\mathrm{PRI}=(5-1)+\frac{-16021,29}{45825,27}
\end{gathered}
$$

Tabla 16. PRI o Payback

\begin{tabular}{rrr}
\hline AÑOS & FLUJO NETO DE EFECTIVO & FLUJO NETO ACUMULADO \\
0 & $-\$ 66.073,08$ & $-\$ 66.073,08$ \\
1 & $\$ 14.181,16$ & $-\$ 53.315,36$ \\
2 & $\$ 15.638,05$ & $-\$ 40.659,11$ \\
3 & $\$ 17.109,56$ & $-\$ 28.201,85$ \\
4 & $\$ 18.596,12$ & $-\$ 16.021,29$ \\
5 & $\$ 45.825,27$ & $\$ 10.981,66$ \\
& PRI & 0,35 \\
\hline
\end{tabular}

Fuente: Elaboración Propia
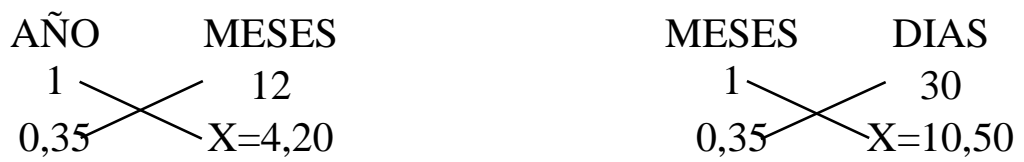

Finalmente, se obtuvo como resultado que la inversión se recuperará en un periodo de 4 años 10 días.

\section{$\underline{\text { Punto de Equilibrio }}$}

Se elabora con el fin de obtener el punto de actividad donde los ingresos totales son equivalentes a los costos totales, en ese punto la empresa no gana ni pierde. Para el análisis del Punto de Equilibrio es necesario clasificar los costos fijos y variables.

Tabla 17. Clasificación de Costos y Gastos Totales

\begin{tabular}{llll}
\hline COSTOS DE PRODUCCION & TOTAL & VARIABLE & FIJO \\
\hline $\begin{array}{l}\text { COSTOS DIRECTOS } \\
\text { Mano de Obra Directa }\end{array}$ & $\$ 35.265,50$ & $\$ 35.265,50$ & \\
\hline
\end{tabular}




\begin{tabular}{|c|c|c|c|}
\hline Materia Prima Directa & $\$ 53.640,00$ & $\$ 53.640,00$ & $\$ 000$ \\
\hline $\begin{array}{r}\text { SUBTOTAL } \\
\text { COSTOS INDIRECTOS DE FABRIC }\end{array}$ & \multicolumn{3}{|c|}{ COSTOS INDIRECTOS DE FABRICACION } \\
\hline Mano de Obra Indirecta & $\$ 28.360,78$ & & $\$ 28.360,78$ \\
\hline Materiales Indirectos & $\$ 465,30$ & & $\$ 465,30$ \\
\hline Suministro de Limpieza & $\$ 727,34$ & & $\$ 727,34$ \\
\hline Servicios Básicos & $\$ 2.825,76$ & & $\$ 2.825,76$ \\
\hline Depreciación Activos Fijos & $\$ 1.857,10$ & & $\$ 1.857,10$ \\
\hline $\begin{array}{l}\text { SUBTOTAL } \\
\text { GASTOS ADMINISTRATIVOS }\end{array}$ & $\$ 34.236,28$ & & $\$ 34.236,28$ \\
\hline Sueldos Personal Administrativos & $\$ 19.381,12$ & & $\$ 19.381,12$ \\
\hline Contador & $\$ 6.711,04$ & & $\$ 6.711,04$ \\
\hline Suministros de Oficina & $\$ 326,83$ & & $\$ 326,83$ \\
\hline Implementación del Plan de Marketing & $\$ 658,80$ & & $\$ 658,80$ \\
\hline Depreciación Activos Fijos & $\$ 647,00$ & & $\$ 647,00$ \\
\hline Amortización Activos Diferidos & $\$ 400,00$ & & $\$ 400,00$ \\
\hline $\begin{array}{l}\text { SUBTOTAL } \\
\text { GASTOS FINANCIEROS }\end{array}$ & $\$ 28.124,79$ & $\$ 0,00$ & $\$ 28.124,79$ \\
\hline Interés de la deuda & $\$ 4.856,37$ & & $\$ 4.856,37$ \\
\hline SUBTOTAL & $\$ 4.856,37$ & $\$ 0,00$ & $\$ 4.856,37$ \\
\hline COSTO TOTAL ANUAL & $\$ 156.122,94$ & $\$ 88.905,50$ & $\$ 67.217,44$ \\
\hline
\end{tabular}

Para determinar el punto de equilibrio debemos fijar primero:

\begin{tabular}{c} 
Costo Variable Unitario= Costos Variables/\# Unidades Producidas \\
Costo Variable Unitario $=\$ 88905,50 / 54000$ \\
CVU $=\$ 1,65$ \\
\hline
\end{tabular}

Margen De Contribucion Unitario $=$ Precio De Venta - Costo Variable
Unitario
Margen De Contribucion Unitario $=\$ 2,94-\$ 1,65$
MCU $=\$ 1,29$
formula:

Para determinar el Punto de Equilibrio en unidades producidas utilizaremos la siguiente

$$
\begin{gathered}
\mathrm{PE}=\frac{\text { Costos Fijos Totales }}{\text { Margen de Contribucion Unitario }} \\
\mathrm{PE}=\frac{\$ 67.217,44}{\$ 1,29} \\
\mathrm{PE}=52062
\end{gathered}
$$

Para determinar el Punto de Equilibrio en valores monetarios utilizaremos la siguiente formula:

$$
\begin{array}{r}
\mathrm{PE}=\frac{\text { Costos Fijos Totales }}{1-\left(\frac{\text { Costos Variables Unitarios }}{\text { Precio de Venta }}\right)} \\
\mathrm{PE}=\frac{\begin{array}{l}
\$ 67.217,44 \\
1-\left(\frac{1,65}{2,94}\right)
\end{array}}{\mathrm{PE}=\$ 152.932,34}
\end{array}
$$




\section{Conclusiones}

KAWSAY es partícipe de ofrecer comida saludable y altamente nutritiva, teniendo en cuenta que la alimentación sana tiene una gran aceptación, además de que el impacto ambiental será bajo para el ecosistema debido a un correcto proceso de reciclaje y manejo de desechos.

Las encuestas realizadas en el estudio de mercado indican que el $98 \%$ de las personas asistirán al restaurante, además se determinará las preferencias de nuestros futuros clientes y así poder trabajar en planes estratégicos para mejorar y satisfacer sus necesidades.

De acuerdo al estudio financiero realizado se concluye que KAWSAY es un proyecto factible y rentable considerando que su TIR es del 16,44\% superior al TMAR de 11,16\%; adicionalmente el VAN es de $\$ 10,981$ lo que garantiza que el presupuesto de inversión inicial es de $\$ 66.073,08$ (el cual será financiado el $75 \%$ con crédito y el $25 \%$ aporte propio) logrará no solo ser recuperado sino también generará una ganancia adicional.

Con respecto al estudio y el enfoque del proyecto, nos indica que KAWSAY tendrá su periodo de recuperación de la inversión en 4 años y 10 días, dando plena certeza y confianza de que el proyecto tiene un futuro viable.

\section{Bibliografía}

Agrotravel. (s.f.). Agrotravel: Turismo Responsable y Sostenible. Obtenido de https://agrotravelturismoresponsable.wordpress.com/2014/10/28/la-gastronomia-sostenible/

Calvente, A. M. (2007). El concepto moderno de sustentabilidad.

Cortés, H., \& Peña, J. (2015). De la sostenibilidad a la sustentabilidad. Modelo de desarrollo sustentable para su implementación en políticas y proyectos. EAN, 15. Obtenido de http://www.scielo.org.co/pdf/ean/n78/n78a04.pdf

El Telegráfo. (2017). Obtenido de http://www.eltelegrafo.com.ec/noticias/economia/8/la-economia-delecuador-se-contrajo-1-5-en-2016

FAO. (2012). Pérdidas y Desperdicio de Alimentos en el Mundo - Alcance, causas y prevención. Roma. Obtenido de http://www.fao.org/docrep/016/i2697s/i2697s.pdf

INEC. (2012). Encuesta Nacional de Ingresos y Gastos de los hogares urbanos y rurales 2011 - 2012. Encuesta, Quito. Obtenido de http://www.inec.gob.ec/Enighur_/Analisis_ENIGHUR\%2020112012_rev.pdf

INEN. (2015). Restaurantes. Sistema de Gestión de Calidad y el ambiente. Requisitos. Quito. Obtenido de http://www.normalizacion.gob.ec/wp-content/uploads/downloads/2015/09/nte_inen_3010.pdf

Instituto Boliviano de Comercio Exterior. (2013). Empresas sustentables para empresarios de hoy que aseguran el mañana. Santa Cruz. Obtenido de https://djlh.files.wordpress.com/2013/11/rseempresas-sustentables.pdf 
Instituto del Medio Ambiente Gylanta. (2001). Huertos Orgánicos: Manual para comunidad. Santiago. Obtenido de http://www.sinia.cl/1292/articles-12888_doc_huertos.pdf

Instituto Nacional de Estadística y Censos. (s.f.). Obtenido de http://www.ecuadorencifras.gob.ec/institucional/home/

Metroecuador. (s.f.). Obtenido de https://www.metroecuador.com.ec/ec/estilodevida/2016/08/16/28millones-ecuatorianos-redes-sociales.html

Ministerio de Agricultura, Ganadería, Acuacultura y Pesca. (2013). El huerto orgánico familiar. Quito. Obtenido de http://balcon.magap.gob.ec/mag01/magapaldia/HOMBRO\%20A\%20HOMBRO/manuales/Manu al\%20El\%20huerto\%20org\%C3\%A1nico.pdf

Prado, M. (2013). Propuesta de un Modelo de Negocio Sostenible para Emprendedores. Obtenido de http://www.significarse.com/wp-content/uploads/2013/11/MODELO-DE-NEGOCIO-

SOSTENIBLE.pdf

Ramírez, J. (2016). El campo Mexicano en la actualidad: La MILPA desde la Gastronomía Sustentable. México. Obtenido de http://www.uagraria.edu.ec/publicaciones/revistas_cientificas/quinta-ola2/CIEA-EA-CMA-006.pdf

Segura, S. (2016). La Difusión de la Campaña "All you need is Ecuador" y su impacto en el turismo receptivo. Empresarial.

SENPLADES. (2013). Plan Nacional del Buen Vivir 2013-2017. Quito. Obtenido de http://www.buenvivir.gob.ec/inicio

Spiegel, M. R., \& Stephens, L. J. (2005). Estadística Schaum. México: McGraw Hill. Superintendencia de Compañias. (s.f.). Obtenido de www.supercias.gob.ec Vida Sostenible. (s.f.). Obtenido de http://www.vidasostenible.org/ 